INTERNATIONAL JOURNAL OF MULTIDISCIPLINARY RESEARCH AND ANALySis

ISSN(print): 2643-9840, ISSN(online): 2643-9875

Volume 05 Issue 02 February 2022

DOI: 10.47191/ijmra/v5-i2-01, Impact Factor: 6.072

Page No.- 244-255

\title{
The Economic and Psychosocial Effects of COVID-19 on Alcohol Use in Grenada during Lockdown: A Discussion on Policy Solutions to Prevent Harmful Alcohol Consumption
}

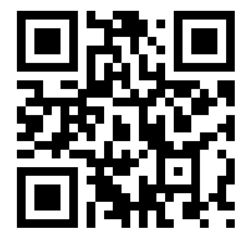

\author{
Shivaughn Hem-Lee-Forsyth, PhD, $\mathrm{MPH}^{1}$, Renee Thomas, $\mathrm{MPH}^{2}$, Leselle Pierre-Romain, $\mathrm{MSc}^{3}$, \\ Cyndica Lewis-Charles, BSc ${ }^{4}$, Cordelle Lazare, MD, MMed ${ }^{5}$, Karl Theodore, MBBS ${ }^{6}$, Skye O'Reilly, \\ MD $^{7}$, Hanna Bryant, MD ${ }^{8}$, Snehali Patel, MD ${ }^{9}$ \\ $1,2,3,5,6,7,8,9$ St. George's University, School of Medicine, Grenada (SGU), \\ ${ }^{4}$ T. A. Marryshow Community College, Grenada
}

ABSTRACT: In Latin America and the Caribbean (LAC) region, there has been an increase in alcohol consumption during the COVID19 pandemic period. The institution of lockdowns and consequent alcohol misuse has been associated with economic challenges and worsening psychosocial conditions. Stress-inducing changes in interpersonal, financial, and broader social dynamics have resulted in increased reports of depression, interpersonal abuse, aggressive behaviours, anxiety, and even suicidality, leading those affected to more frequent and more heavy alcohol use as a coping mechanism. This review focused on trends of alcohol use during the pandemic in Grenada, and it also explored the economic and psychosocial factors that contributed to adverse outcomes of alcohol use. In response to the destructive coping strategies associated with deteriorating mental health, the paper also proposed vigorous policy changes to mitigate the ongoing misuse of alcohol, particularly during future crises. Library databases, webpages of various governments and international agencies, and peer-reviewed journal sources were searched for data on global alcohol consumption during the 2020-2021 COVID-19 lockdown periods, focusing on Grenada. A total of 64 sources published between 1979-2021 were included based on their relevance. The COVID-19 pandemic has highlighted the importance of building resilient public health systems and addressing public health concerns such as excessive alcohol consumption.

KEYWORDS: Alcohol use, alcohol consumption, Grenada COVID-19 lockdown, healthcare resources, economic issues, psychosocial concerns, health policy, policy implications

\section{INTRODUCTION}

Alcohol is associated with significant mortality, and morbidity secondary to its higherthan-average consumption levels in the Americas compared to the rest of the world (Pan American Health Organisation [PAHO], 2020). Alcohol is also implicated in weakening the immune system, diminishing quality of life, and lowering life expectancy. Indeed, heavy alcohol consumption increases susceptibility to various infections and complications, as with COVID-19 and the associated acute respiratory distress syndrome (PAHO, 2020). Alcohol consumption also contributes to intensified risky behaviour and disease states that worsen the quality of life, including obesity, diabetes, and hypertension. An increase in drinking also exacerbates health spending, reduces employment, lowers educational outcomes, and decreases overall productivity (Organisation for Economic Co-operation and Development [OECD], 2021). More broadly, alcohol abuse has been associated with behaviour leading to increased injury, including motor vehicle accidents and various forms of violence (OECD, 2021).

There is a sequela of alcohol misuse that has always existed globally. As the pandemic has evolved, however, there has been an increase in domestic abuse, aggressive behaviour, and child abuse and neglect, of which heavy drinking is a predisposing risk factor (OECD, 2021). These findings were evidenced by a study that identified a rise in domestic violence and an increased risk of harm to children or self that were associated with increased alcohol consumption (Ramalho, 2020). As a result of lockdowns and social distancing measures and a subsequent shift of drinking behaviours from social settings to inside the home, there was also an increase in drinking in the presence of children (Garcia-Cerde et al., 2021). Frequent parental alcohol consumption may undermine the negative consequences of its use while enhancing its positive aspects, leading to the early initiation of alcohol consumption in teenage children (Garcia-Cerde et al., 2021). 


\section{The Economic and Psychosocial Effects of COVID-19 on Alcohol Use in Grenada during Lockdown: A Discussion on Policy Solutions to Prevent Harmful Alcohol Consumption}

Regarding accessing health care resources and rehabilitation, these data make alcohol a considerable risk factor for worsening the burden of any health care system. Despite alcohol's use as a relaxation method to counter the pandemic's stressors, alcohol consumption increases the risk of contracting SARS-CoV-2. Those living with a mental illness are particularly vulnerable to psychological decline, especially in the context of social distancing and, in some cases, isolation (Calina et al., 2021). Therefore, governments must implement programs and policies to effectively monitor and manage alcohol consumption and related complications, particularly during crises. This literature review explores the economic and psychosocial factors that contribute to alcohol consumption during the COVID-19 pandemic, and it also examines various established policies worldwide and in Grenada aimed at regulating alcohol use.

\section{ALCOHOL USE IN LATIN AMERICA AND THE CARIBBEAN}

The injection of the COVID-19 pandemic into the world has dismantled life on social, cultural, and personal levels. Around the globe, people have been grappling with fear, panic, and uncertainty as they struggle to adjust to the effects of imposed social distancing and isolation associated with lockdowns. A common thread throughout the literature shows that the ramifications of lockdown imposition continue to have the most notable impact. Restrictive environments create a bubble for many, which may be detrimental to their personal and social lives (Ramalho, 2020). These measures can affect individuals' well-being in a variety of ways and can lead to extreme stress. Such stress and isolation can be a breeding ground for substance abuse of many forms, including alcohol, a substance that is easily accessible (Ramalho, 2020).

Several studies have shed light on multiple risk factors for increased alcohol use. In the region of Latin America and the Caribbean (LAC), research has shown that being both male and wealthy has been associated with a higher frequency of drinking behaviours. Being quarantined was positively associated with a higher frequency of online social drinking and drinking in the presence of children (Garcia-Cerde, 2021). Male gender, higher income, and a higher level of quarantine practices increased the risk for more frequent episodes of heavy episodic drinking (HED) (Valente et al., 2021). Research illustrates that the management of non-communicable diseases (NCDs) during the COVID-19 pandemic has been impacted, as many experienced a decrease in available resources. In turn, there was an increase in behavioural risk factors that exacerbate NCDs, such as increased alcohol use, with the Americas (including LAC) demonstrating the highest rates of alcohol misuse (WHO, 2020). Since the onset of the COVID19 pandemic, economic and social living conditions have changed in many ways - from the national, state, county and parish level to personal changes limited to the family unit or individual community member. Implementation of several measures by governments to mitigate the spread of infection included lockdowns of varying degrees. It is common knowledge that lockdown orders necessitated the disruption and even closing of many non-essential businesses, leading to a spectrum of economic crises. Some individuals lost their jobs, some worked reduced hours, while a section worked, studied, or stayed at home for the duration of the lockdown.

According to the Organisation for Economic Co-operation and Development (2021), Australia, Austria, Brazil, France, Germany, Ireland, the Netherlands, New Zealand, Switzerland, the United Kingdom, and the United States reported increased consumption of alcohol between May and June 2020 in 36\% of study participants. In Non-Latin Caribbean areas, respondents reported an increase in wine and spirits consumption from March to June 2020 of the pandemic (PAHO, 2020). These outcomes may be related to multiple government-led lockdowns and stringent measures to contain the virus (OECD, 2021). McPhee et al. (2020) determined a comparable increase in alcohol consumption during the pandemic's social distancing phase compared to its pre-pandemic counterpart. Other research revealed a $477 \%$ increase in online alcohol sales by the end of April 2020, although this statistic may be inflated due to the concomitant closure of bars and decreased frequenting of restaurants in general (Calina et al., 2021). Other data, however, demonstrated an overall decrease in the prevalence of drinking from March through June of 2020 (PAHO, 2020). In Non-Latin Caribbean areas, this statistic was consistent with decreased beer consumption and homemade alcoholic drinks. Although the overwhelming majority in this region reported no change in frequency of HED from 2019 to 2020 , a more significant percentage reported decreased (17.2\%) rather than increased $(9.7 \%)$ frequency of such drinking behaviours (PAHO, 2020). Still, of the respondents who reported engaging in HED, there was a 3.5\% decrease in help-seeking behaviour from 2019 to 2020 (PAHO, 2020).

The injection of the COVID-19 pandemic into the world has dismantled life on social, cultural, and personal levels. Around the globe, people have been grappling with fear, panic, and uncertainty as they struggle to adjust to the effects of imposed social distancing and isolation associated with lockdowns. A common thread throughout the literature shows that the ramifications of lockdown imposition continue to have the most notable impact. Restrictive environments create a bubble for many, which may be detrimental to their personal and social lives (Ramalho, 2020). These measures can affect individuals' well-being in a variety of 


\section{The Economic and Psychosocial Effects of COVID-19 on Alcohol Use in Grenada during Lockdown: A Discussion on Policy Solutions to Prevent Harmful Alcohol Consumption}

ways and can lead to extreme stress. Such stress and isolation can be a breeding ground for substance abuse of many forms, including alcohol, a substance that is easily accessible (Ramalho, 2020).

Historically, research has illustrated an association between pandemic stressors and increased prevalence of alcohol use disorder (AUD) and alcohol-related harms. This relationship was manifested during Beijing's 2003 SARS outbreak: hospital employees reported increased alcohol abuse and dependence symptoms (Ramalho, 2020). In a cross-sectional study conducted in the United States, participants who reported extreme stress due to the COVID-19 pandemic also disclosed higher alcohol consumption (Grossman, Benjamin-Neelon \& Sonnenschein, 2020). Participants reported increased alcohol consumption at home in parallel studies across countries like China, the UK, Germany, and Brazil (Garcia \& Sanchez, 2020). Overall, those "reporting economic worries, those quarantined and those studying or working at home" were more likely to report hazardous drinking behaviour (Garcia \& Sanchez, 2020; Alpers et al., 2021, p. 5).

Beyond public health crises, increased alcohol use is a trend that has been noted amidst natural disasters as well. An association between exposure to stressful aspects of a natural disaster and self-perceived changes in alcohol consumption was found in a study conducted among repatriated Norwegians who resided in Southeast Asia during the 2004 tsunami (Nordløkken et al., 2016). Similarly, in the United States, those diagnosed with post-traumatic stress disorder after Hurricane Sandy (2015) were more likely to engage in binge drinking (Locke et al., 2020). In addition to excessive alcohol consumption, natural disasters' resulting economic and physical strain often leads to other increased harmful behaviours such as violence (Charveriat, 2000).

\section{TIMES OF CRISIS: ALCOHOL CONSUMPTION IN GRENADA}

Previous yet limited studies in the Caribbean have demonstrated a negative correlation between alcohol use and mental health in times of crisis. Per the patterns in Southeast Asia and the United States mentioned above, there has been an increase in alcoholrelated problems in Caribbean countries following natural disasters such as hurricanes, especially those living in shelters (Gordon Stair \& Pottinger, 2005). There is evidence that $29 \%$ of people who live in LAC are affected yearly by natural disasters. According to a Grenadian sociologist, Hurricane Ivan was recorded as the worst natural disaster to strike Grenada, resulting in thirty-nine casualties (Douglas, 2006). While limited research has evaluated alcohol use during natural disasters, empirical evidence has shown a positive relationship between exposure to natural disasters and alcohol use.

Like other Caribbean territories, alcohol consumption in Grenada is deeply rooted in the country's social and cultural norms (Japal \& Benoit, 2017), with an average daily intake of pure alcohol at 40.4 grams exceeding the world's average of 33 grams (Campbell, 2018). According to the 2018 Global Status Report on Alcohol and Health, trends in recorded Grenadian alcohol per capita consumption trend have favourably seen a decline from 12.5 litres in 2014 to 9.3 litres in 2018. However, per capita consumption of unrecorded alcohol increased from $0.7 \%$ in 2014 to $1.4 \%$ in 2018 (Campbell, 2018). Despite the decline of recorded alcohol consumption, HED has increased among drinkers, with the majority consuming spirits and beer (Campbell, 2018). HED has been shown to become even more concerning during pandemic lockdowns, a reason why it is pertinent to continually monitor the rate of alcohol consumption. Like other countries, Grenada took proactive measures to reduce the spread of COVID-19 by instituting curfews and restricting movement. While these efforts aided in curbing the sale and consumption of alcohol, the established infrastructure was not equipped to manage such measures' psychosocial repercussions effectively.

Despite the alarming baseline rate of alcohol consumption in the country, Grenada's sole rehabilitation facility, Carlton House Treatment Center, has been operating on a significantly reduced workforce since 2006 (GBN, 2020). As a result of the limited capacity, there remains a lack of support services available for individuals who struggle with substance abuse. Consistent with global trends, it can be deduced that Grenada's demand for these services has been exacerbated during the COVID-19 period. As Grenada grapples with the impact of the COVID-19 pandemic, especially during lockdown periods, it is imperative to evaluate how economic and psychosocial factors impact alcohol consumption. Of equal importance is enabling access to support services that aim to minimise the overall impact of alcohol consumption on one's social, emotional, and mental health. In total, findings from this review paper will address the gaps in the literature regarding the impact of COVID-19 on the fibre of Grenadian society. They will also form the foundation for new policy interventions that address alcohol use for the remainder of the COVID-19 pandemic and beyond, as the extent of the psychological impact of this pandemic is only beginning to be elucidated.

\section{METHODOLOGY}

A literature review was conducted to identify sources discussing alcohol use globally during the 2020-2021 COVID-19 lockdown period, concentrating on the Caribbean region and Grenada. The literature search focused on the following themes: (i.) economic factors that contributed to alcohol use during the lockdown period; (ii.) the psychological impact of alcohol use on physical, emotional and mental health; (iii.) existing and proposed measures (policies and programs) that can be taken to address excessive 


\section{The Economic and Psychosocial Effects of COVID-19 on Alcohol Use in Grenada during Lockdown: A Discussion on Policy Solutions to Prevent Harmful Alcohol Consumption}

alcohol consumption. Analysis of peer-reviewed articles and reports from regional and international public health agencies, including but not limited to the World Health Organization and the Pan-American Health Organization, were included in this literature review. Additionally, webpages of the Government of Grenada, Government of the United Kingdom, the Governor's Highway Safety Association, the World Bank, the International Monetary Fund, the Organisation for Economic Co-operation Development, and the United States National Bureau of Economic Research were used to access fact sheets and reports. The primary tools used for the literature search were PubMed, Google Scholar, ScienceDirect, Embase, Scopus, ProQuest, and Web of Science.

The databases were searched using the keywords "alcohol use" and "alcohol consumption" cross-referenced with "attitudes," "knowledge," "practices," "health care resources," "Caribbean," "Grenada," "natural disasters," "hurricane," "economic factors," "socioeconomic factors," psychological factors," "psychosocial factors," "social factors," "mental illness," "domestic violence," "suicide," "policy," "COVID-19," "2019-nCoV," and "pandemic." The relevance of articles of the themes under study was assessed using their titles, abstracts, and conclusions. The literature inclusion criteria were based on publications in English within the previous twenty years and based on full-text availability. Data sources were excluded if they were conferences, publications addressing alcohol consumption but not during times of disaster, substance abuse evaluation of substances other than alcohol, or addressed other extraneous factors impacting and contributing to alcohol consumption. A total of 64 data sources were used in this literature review. Of these sources, 22 were related to economic factors that contributed to alcohol use during the lockdown period; 14 were related to the psychological impact of alcohol use on physical; and 30 were related to emotional and mental health, as well as measures that can be taken to address excessive alcohol consumption. A total of 58 sources included were published within the last twenty years. Six sources beyond this period were included due to the relevance of their content to the subject matter. Unfortunately, the search produced limited studies conducted in the Caribbean region and Grenada on COVID-19 and alcohol use.

\section{ECONOMIC FACTORS}

In April 2020, during the initial stages of the COVID-19 pandemic, the International Monetary Fund (IMF) reported a global economic contraction of 3\%, akin to the contraction experienced in the worldwide recession of 2008-09. In an attempt to protect lives and allow health care systems to manage the sudden increase in demand for emergency and intensive services, various countries employed stay-in-place orders. Regulations included lockdowns, home isolations, the closure of state borders, and the halting of activity from several sectors, especially where physical interaction was inevitable. As a result, economic activity substantially slowed, and the full extent of the fallout has yet to be determined (International Monetary Fund, 2020).

Economic crises or contractions within a country may usher in the loss of jobs, income, promotion, and wealth (Ruhm, 1995; Amadeo, 2021). These consequences, in turn, have been associated with intensified mental health complications and a myriad of other health conditions, including high rates of cirrhosis and cardiovascular disease (Brenner, 1979). The COVID-19 pandemic has caused an economic downturn, which is considered one of the most severe experienced in the last 100 years (Alcohol Change U.K., 2020). The OECD has anticipated that these economic effects "will cast a long shadow over the world" (Walker, 2020, para 3), indicating the geographical and temporal immensity of the situation.

Grenada experienced a period of economic contraction during its lockdown due to COVID19 (World Bank, 2020). As with other Small Island Developing States (SIDS), Grenada's primary financial industry is tourism. As policies were established to curb the spread of COVID-19, there was a consequent suspension of tourism activities and other profitable industries, causing a reduction in economic growth by about 12-15 per cent (World Bank, 2020). This economic downturn experienced by Grenada is not unlike those faced by other countries over the years. For example, the United States of America has endured several economic crises, most notably during the Great Depression of the 1930s and, more recently, the Great Recession in 2008 (Amadeo, 2021).

Similar to Grenada's economic contraction, the economies of more developed countries have also been negatively impacted by COVID-19. The National Bureau of Economic Research (2021) informed that the U.S. economy saw a halt in its economic growth in February 2020 - its first downturn since 2009. During the subsequent year, the U.S. experienced a contraction in its economy due to a series of outcomes from the pandemic and policies to protect the public (Bauer et al., 2020). Some of these outcomes included increased unemployment, worsening food insecurity, and the inability of some families to make monthly rent payments (Bauer et al., 2020). Countries in East and Central Asia, The Pacific, and Europe experienced comparable economic consequences of the pandemic (World Bank, 2020).

There is an abundance of conflicting evidence on whether economic downturns and contractions decrease or increase alcohol consumption (Alcohol Change U.K., 2020, Goeij et al., 2015). According to Ruhm (1995), health is an economic good such that changes in incomes and earnings are related to differences in health outcomes. For example, loss of income can lead to loss 


\section{The Economic and Psychosocial Effects of COVID-19 on Alcohol Use in Grenada during Lockdown: A Discussion on Policy Solutions to Prevent Harmful Alcohol Consumption}

of health insurance, resulting in adverse health outcomes. According to Skog (1986) and Wagenaar and Streff (1989), income is positively correlated with consumer goods such as alcohol, implying that as income increases, alcohol consumption increases and vice versa. Dziadkiewicz et al. (2015) agreed that the demand for goods and services would change depending on an individual's income because of Income Effect Theory. Therefore, if alcohol is classified as a normal good, as income decreases during an economic contraction due to unemployment, alcohol consumption should also reduce (Popovici and French, 2013). It is proposed that this reduction in consumption occurs secondary to an imperative(necessary) focus on more essential items such as food, clothing, and bills during these periods.

Catalano and Bellows (2005) favour policies that encourage economic contractions because an inhibition effect during a recession purportedly results in workers demonstrating safer behaviours and public health practices such as a reduction in cigarette use and alcohol intake, as well as an increase in exercise. Catalano et al. (1997) described the inhibition effect as one where a person may become the ideal employee out of fear of losing their job, which translates to better health outcomes. With job insecurities relatively high during a recession, people are inclined to drink less alcohol to avoid attracting attention and risking their jobs (Alcohol Change U.K., 2020).

In the U.K., it has been found that $43 \%$ of employees believe that they have experienced peer pressure to consume alcohol during work social events (Webber, 2019). Amidst the pandemic, this statistic could imply reduced alcohol consumption among individuals who have lost their jobs and those still employed, but in the absence of peer pressure (Alcohol Change U.K., 2020). However, during economic downturns, it has been observed and documented that, despite this reasoning as to why alcohol consumption might decline, there is also evidence of its increase (Goeij et al., 2015). Goeij et al. (2015) found that persons who experience a reduction in income due to an economic recession turn to cheaper alcohol forms or even home distilling. Doran and Digiustio (2011) and Karlsson et al. (2010) observed that during crises in Finland and Australia, the consumption of distilled spirits declined, but there was an uptick of beer, wine, and cider. Likewise, in Russia, persons switched from purchasing alcoholic beverages to making and consuming their own (Perlman, 2010).

Furthermore, it has been found that people substitute drinking at bars, which entails an appreciable product markup, to drinking at home (Munne, 2005). An example of this shift was documented during an economic crisis in Argentina. The evidence revealed that $75 \%$ of the study population knew individuals who stopped visiting bars but instead consumed alcohol at a friend's or their own home (Munne, 2005). These debates on the surge versus reduction of alcohol consumption secondary to economic circumstances should not be analysed in isolation, as various factors influence a person's decision to partake in increased or decreased alcohol use.

\section{PSYCHOSOCIAL FACTORS}

Several patterns emerge upon reviewing the recent literature investigating alcohol use and individual and societal health during lockdown periods throughout the COVID-19 pandemic. There have been numerous repercussions on mental and emotional health. Overall, the social distancing and isolation resulting from mandated lockdowns are associated with increased reported depressive symptoms (McPhee et al., 2020; Alpers et al., 2021; Killgore, Cloonan, Taylor, Lucas, \& Dailey, 2021). As social creatures, humans thrive when allowed to assemble and engage in social interactions. During lockdown times, however, residents are limited with such exchanges and are at increased risk of psychological decline (Bell et al., 2021; Alpers et al., 2021). Concerns other than restricted social interactions also contribute to increased psychological distress (Bell et al., 2021; Tsai et al., 2021). These sources of stress include economic uncertainty and employment insecurity; housing instability; anxiety surrounding SARS-CoV-2 infection of self or others; strained interpersonal relationships, and reduced access to mental health services (Killgore et al., 2021). Collectively, these changes in social, financial, and psychological functioning are associated with a greater tendency to drink alcohol as a coping mechanism, which is a predictor of increased alcohol consumption both in frequency and quantity (McPhee et al., 2020; Valente et al., 2021; Alpers et al., 2021).

In general, stress or trauma can cause disruptive usage of alcohol. In a cross-sectional study conducted in the United States, participants who reported extreme stress due to the COVID19 pandemic also reported higher alcohol consumption (Grossman, Benjamin-Neelon \& Sonnenschein, 2020). On a global scale, during the COVID-19 pandemic, women, parents of young children, people with higher income, and those with previously diagnosed anxiety and depression reported the most significant increase in alcohol consumption (OECD, 2021). In their study on alcohol dependence, Killgore et al. (2021) concluded that alcohol consumption is most notable among persons who lost their jobs during the pandemic. In the U.S., greater alcohol consumption was associated with younger age, male sex, and direct job loss due to the pandemic (Killgore, 2021). Douglas (2019) suggested that alcohol acts as a "magic potion or solution" to cope with stressful situations and is a means to manage personal problems among young people. Therefore, one can deduce that alcohol becomes a coping mechanism to manage stressful situations. 


\section{The Economic and Psychosocial Effects of COVID-19 on Alcohol Use in Grenada during Lockdown: A Discussion on Policy Solutions to Prevent Harmful Alcohol Consumption}

Consistent with the behavioural and self-medication theories, more glaring social and environmental constraints and increased psychological distress during COVID-19 can result in increases in depression and drinking to cope with negative affect (McPhee et al., 2020). Tsai et al. (2021) found that a total of 35.3\% of people in the U.S. screened positive for current AUD. The number of close friends, history of AUD, anxiety disorder, and younger age was significantly associated with screening positive for AUD (Tsai et al., 2021). Conversely, in a Thailand survey, the Government banned alcohol purchases at the beginning of the pandemic. As a result, prepandemic drinkers either abstained from alcohol or consumed fewer drinks than usual during the prohibition of alcohol sales (Wichaidit, 2021). These findings reveal how government policy can have a direct effect on alcohol consumption and resulting behaviours.

Indicative of the bidirectionality of these relationships, increased alcohol consumption is negatively associated with psychological well-being. Persons who use alcohol as a coping strategy for pandemic stressors report higher depression, anxiety, and stress (Stanton et al., 2020; Chodkiewicz et al., 2020). Increased alcohol consumption during lockdown has also exposed incidences of increased domestic violence and increased depression and anxiety in those not previously diagnosed (OECD, 2021). Further, persons who have been diagnosed with a mental illness before the start of the COVID-19 pandemic demonstrate an increased risk of deterioration of mental well-being during lockdown periods. In particular, a previous psychiatric diagnosis is a risk factor for increased anxiety, depression, suicidality, and, in turn, increased alcohol use (Bell et al., 2021; Tsai et al., 2021; PAHO, 2020). Notably, reported psychological distress in conjunction with AUD is associated with an increased risk of suicidality (Tsai et al., 2021). This distress is further supported by Bell et al. (2021), who found that increased alcohol use was associated with increased thoughts of suicide among persons with mental health issues.

Moreover, the World Health Organisation (WHO) warns that alcohol consumption can increase during self-isolation, and combined elements can increase the risk of suicide (WHO, 2020). Even more concerning, persons who report HED, or the consumption of about five alcoholic drinks on one occasion, demonstrate a decrease in help-seeking behaviour during the COVID19 pandemic compared to prior (PAHO, 2020). These outcomes highlight the importance of enhancing access to mental health resources during distressing events.

As evidenced by the literature, the COVID-19 pandemic has dramatically changed people's lives and livelihoods. To manage stressors - loss of a job, loss of free movement, fear of contracting the virus, uncertainties relating to the COVID-19 pandemic, and changes to everyday living - persons used alcohol as a coping mechanism. Although research illustrates that alcohol is consumed primarily in social settings, the COVID-19 pandemic changed this dynamic. Alcohol was more frequently and more heavily consumed in the home, which aggravated many psychosocial issues outlined in the research: interpersonal violence, depression, loneliness, anxiety, and increased suicidal ideation - all of which have emerged as significant issues within the COVID19 context.

\section{POLICY AND PROGRAM RECOMMENDATIONS}

As highlighted in this paper, excessive alcohol consumption is a significant concern, and it is imperative to implement public health policies and programs to mitigate its harmful effects. There are common policy interventions that have been implemented in OECD countries, such as taxes on alcoholic beverages, blood alcohol concentration limits for drivers, and age restrictions for purchase and consumption (OECD, 2021). While these evidence-based policies are not directly adaptable to Grenada without exploring the historical and socio-cultural practices underlying common drinking behaviours, valuable lessons can be drawn from the efforts undertaken by other countries, particularly those that emphasise policies focused on promoting public health.

\section{POLICY LESSONS FROM THE OECD COUNTRIES}

The age requirement for the purchase of alcohol in Grenada is a minimum of 16 years of age (Liquor Dealers' Licence Act, 1988), lower than most countries, including the United States (Center for Disease Control and Prevention, 2020), the United Kingdom (Government of the United Kingdom, n.d.), Australia (Australian Government Department of Health, 2020) and Bermuda (Liquor License Act, 1974). In 1997, The United Nations Children's Fund (UNICEF) reported that Grenada's provisions regarding the sale, supply, and delivery of alcohol to minors do not adequately ensure that those under 16 refrain from using or purchasing alcohol. It is noteworthy that Grenada's Liquor Dealers' Licences Act was last amended in 1988 (Liquor Dealers' Licences Act, 1988). To ensure public safety and reduce the early initiation of early alcohol exposure, policymakers in Grenada should consider reviewing the existing legislation. Two key areas that can be enhanced within that legislation include increasing the legal age limit for the purchase of alcohol from 16 to 18, equivalent to other Caribbean islands such as Barbados (Barbados Today, 2021), and strengthening the enforcement of existing legislation following the feedback from UNICEF. These adjustments will reduce the early initiation of alcohol and ensure that the legislation adequately protects those under the legal drinking age. 


\section{The Economic and Psychosocial Effects of COVID-19 on Alcohol Use in Grenada during Lockdown: A Discussion on Policy Solutions to Prevent Harmful Alcohol Consumption}

Another policy solution is alcohol excise taxes. Alcohol is typically taxed in three different ways: the volume of the alcoholic beverage, the ethanol content, or the value of the alcoholic beverage (OECD, 2021). In Grenada, alcoholic beverages are taxed at a flat rate, either XCD 1.10 per litre for wines or XCD 4.40 per litre for all other alcoholic beverages (Government of Grenada, 2021)). To encourage manufacturers to reduce the alcohol content of beverages, taxes based on the volume of alcohol content tend to be favourable. In South Africa, a beer-excise tax based on ethanol content was implemented, leading manufacturers to produce and market lower-content alcohol products more aggressively (Chaloupka et al., 2019). Correspondingly, in Grenada, the alcohol manufacturing industry and other key stakeholders should be engaged in discussions to adjust the existing excise tax structure to discourage excessive alcohol consumption. As previously highlighted, alcohol is a normal good, suggesting that demand decreases as price increases. Hence it is worth exploring altering the existing tax structure to reduce the demand for high alcohol content beverages.

\section{PROGRAMS IN PRIMARY CARE SETTINGS}

Many countries have taken steps to address the adverse impacts of excessive alcohol consumption by introducing screening and prevention programs in the primary care setting (Kaner et al., 2018; Angus et al., 2014; O'Donnell et al., 2014). Several European and North American studies have investigated the knowledge, attitudes, and practices concerning health care resources for alcohol use. Nonetheless, establishing the necessary alcohol screening and intervention programs has been slow (O'Donnell \& Kaner, 2017; Brown et al., 2016; Nilsen et al., 2011). Many/Most health care professionals remain optimistic that this issue can be addressed with adequate training (Mcmanus et al., 2003). Due to several factors, however, some maintain a more pessimistic outlook, thus hindering the widespread implementation of alcohol screening and prevention programs. These factors are multifaceted: a lack of knowledge and skillset to detect alcohol problems; the belief that healthcare professionals cannot indeed generate behavioural changes in patients with alcohol use issues; fear of offending patients due to the delicate subject matter; difficulty stimulating dialogue with patients who are not actively seeking assistance for alcohol-related problems; and perceived lack of time as health care professionals already feel overworked (Mcmanus et al., 2003; Johansson et al., 2005; Nilsen et al., 2011).

The literature presents some contradicting data: it indicates that patients widely support integrating alcohol screening and prevention programs into routine primary care. Multiple European and North American studies have reported that patients essentially welcome regular alcohol screening and are comfortable discussing the issue of personal alcohol use with health care professionals (O'Donnell et al., 2018; Aalto et al., 2003; Field et al., 2013; Hutchings et al., 2006; Miller et al., 2006; Broyles et al., 2012). While there is no related study in Grenada, it may be prudent to engage physicians, other healthcare providers, and patients in the possibility of instituting screening and prevention programs within the primary care setting. While execution may seem like a daunting task, this can be done in a phased manner, starting with the Public Medical Stations and Health Centers. The realisation of alcohol prevention and screening programs will require extensive training for all health care professionals within the system to ensure that they are sufficiently equipped to engage, assess, and refer patients to the relevant professionals.

\section{FUTURE DIRECTION FOR GRENADA}

Undoubtedly Grenada has generated efforts to address excessive alcohol consumption. In 2019, the Royal Grenada Police Force announced the use of breathalyser tests by police officers to assess the blood alcohol level of drivers (Grenada Broadcasting Network, 2019). In this report from Grenada's Broadcasting Network Newsroom, it was reported to the nation that the legal limit would be 160 milligrams of alcohol in 100 millilitres of blood. This measure is key to addressing drunk driving proactively and potentially reducing road accidents due to driving under the influence of alcohol. While this is a step in the right direction, this limit is double the rate in other countries, such as the United Kingdom (Drinkaware UK, 2021) and the United States (Governor's Highway Safety Association, 2021). While the socio-cultural norms of Grenada were considered when implementing this policy, it is essential to reevaluate the effectiveness of these regulations toward protecting the public's health.

Additionally, there have been several enhancements to Grenada's National School's Policy on Drugs for the period of 2018-2023. In 2019, the then Minister of Education announced that the sale of alcoholic beverages would be prohibited at school functions (Now Grenada, 2019). This pronouncement was a critical juncture in reducing the exposure of alcohol consumption to children. Within that policy, it was also highlighted that any drunk teacher while on duty would be guilty of misconduct (National School Policy on Drugs, 2018). These policy changes were wellreceived public health initiatives designed to protect children and reduce exposure to alcoholic beverages. However, it is important to explore how these policies might be strengthened, such as prohibiting any amount of alcohol consumption by teachers during school activities. It is also imperative to consider psychosocial 


\section{The Economic and Psychosocial Effects of COVID-19 on Alcohol Use in Grenada during Lockdown: A Discussion on Policy Solutions to Prevent Harmful Alcohol Consumption}

support for students exposed to excessive alcohol consumption by their teachers or parents, who in turn may be at risk for early initiation of alcohol consumption themselves.

There are a variety of policies and programs that can be explored to reduce excessive alcohol consumption in Grenada. As Catalano and Bellows (2005) suggest, it may not be feasible to rely on an economic recession since numerous challenges accompany an economic decline. However, other policy solutions that will otherwise have a minor impact on society can be explored. These endeavours should be a synergistic effort between the Government of Grenada, Non-Governmental Organisations (NGOs), Faith-Based Institutions, Professional Bodies, Community Groups and other sectors within the society. This collaborative approach can yield policies that are well-received by the community. In a study conducted in East Africa, it was observed that NGOs played a crucial role in alcohol prevention and policy development; however, there is a need for broader and more substantial support to facilitate effective campaigns (Kasirye, R. \& Swahn, M., 2015). To avoid duplication of efforts and maximise resources effectively, various stakeholder groups should be engaged regularly to discuss policy solutions, implementation strategies, and minimisation of complications related to excessive alcohol consumption. While this may be a challenge for the leadership of the Government of Grenada to undertake independently, Non-Governmental Organisations and Interest Groups can play a pivotal role with the necessary support, leadership and resources from the Government.

\section{CONCLUSION}

The ongoing COVID-19 pandemic has exposed the vulnerabilities of public health systems worldwide (Benjamin, 2020) and highlighted the urgency to build resilient health systems. As with many Small Island Developing State (SIDS), Grenada has been grappling with existing economic, social, and environmental hardships (OECD, 2015), and the response to the pandemic placed an even more pronounced burden on the society.

Excessive alcohol consumption is an ongoing concern in Grenada, with the average daily intake of pure alcohol higher than the world's average. It is paramount to evaluate existing economic and psychosocial factors contributing to excessive alcohol consumption among Grenada's population, especially in the wake of the pandemic's increased stressors. This exploration will provide a deeper understanding of the social determinants that inadvertently contribute to excessive alcohol consumption, which will aid policymakers in assessing existing policies and proposing amendments to meet the population's needs.

Policy adjustments will require active engagement with the community and key stakeholder groups (NGOs, Community Organizations, and Businesses) to ensure that updated policies reflect society's values. This approach fosters trust and encourages public participation in policymaking (Alemanno, 2015). The COVID-19 pandemic has highlighted the importance of working collaboratively to address a public health crisis. Grenada continues to forge ahead amidst the pandemic, engaging various stakeholder groups to address the existing and worsening problem of excessive alcohol consumption. The proposed solutions should be rooted within the context of the current global pandemic while looking forward and taking proactive measures to address the problem beyond the current situation. This approach will require ongoing evaluations to determine the effectiveness of existing policies and appropriate modifications to achieve the desired public health goal.

The literature has demonstrated the timeliness and gravity of investigating excessive alcohol consumption in Grenada, particularly during a crisis such as the COVID-19 pandemic. There is limited information on alcohol consumption in Grenada during this period, making it a challenge to evaluate the extent of the problem thoroughly and accurately. This review will be followed by a research study exploring the scope of alcohol use during the lockdown period and its impact on the people of Grenada. The findings will provide policymakers and public health professionals with a foundation to create policies and programs to address excessive alcohol consumption during a crisis and beyond.

\section{REFERENCES}

1) Aalto, M., Pekuri, P., \& Seppä, K. (2003). Obstacles to carrying out brief intervention for heavy drinkers in primary health care: A focus group study. Drug and alcohol review, 22(2), 169-173. https://doi.org/10.1080/09595230100100606

2) Alcohol Change U.K. (2020, September). Casting a long shadow: What might a coming economic downturn mean for alcohol consumption and harm? Retrieved from https://s3.euwest 2.amazonaws.com/files.alcoholchange.org.uk/images/Casting-a-long-shadow-1.pdf

3) Alemanno, A. (2015, November 15). Stakeholder Engagement in Regulatory Policy. SSRN. https://papers.ssrn.com/sol3/papers.cfm?abstract_id=2701675

4) Alpers, S. E., Skogen, J. C., Mæland, S., Pallesen, S., Rabben, Å. K., Lunde, L. H., \& Fadnes, L. T. (2021). Alcohol consumption during a pandemic lockdown period and change in alcohol consumption related to worries and pandemic measures. International Journal of Environmental Research and Public Health, 18(3), 1220. 
The Economic and Psychosocial Effects of COVID-19 on Alcohol Use in Grenada during Lockdown: A Discussion on Policy Solutions to Prevent Harmful Alcohol Consumption

https://doi.org/10.3390/ijerph18031220

5) Amadeo, K. (2021). What is an Economic Contraction? The balance. Retrieved October 9, 2021, from https://www.thebalance.com/economic-contraction-4067683

6) Angus, C., Scafato, E., Ghirini, S., Torbica, A., Ferre, F., Struzzo, P., Purshouse, R., \& Brennan, A. (2014). Cost-effectiveness of a programme of screening and brief interventions for alcohol in primary care in Italy. BMC Family Practice, 15, 26. https://doi.org/10.1186/1471-2296-15-26

7) Bauer, L., Broady, K., Edelberg, W., O'Donnel, J., (2020), Ten facts about COVID-19 and the U.S. economy. Brookings. https://www.brookings.edu/research/ten-facts-about-covid-19and-the-u-s-economy/

8) Bell, C., Williman, J., Beaglehole, B., Stanley, J., Jenkins, M., Gendall, P., Rapsey, C., \& EveryPalmer, S. (2021). Psychological distress, loneliness, alcohol use and suicidality in

9) New Zealanders with mental illness during a strict COVID-19 lockdown. Australian \& New Zealand Journal of Psychiatry, OO(0), 1-11. https://doi.org/10.1177/00048674211034317

10) Benjamin GC. Ensuring health equity during the COVID-19 pandemic: The role of public health infrastructure. Rev Panam Salud Publica. 2020;44:e70. https://doi.org/10.26633/RPSP.2020.70

11) Brenner, M.H. (1979). Influence of social environment on psychopathology: The historical perspective, in James E. Barret et al., eds., Stress and Mental Disorder. Raven Press, New York. 161-177.

12) Brown, J., West, R., Angus, C., Beard, E., Brennan, A., Drummond, C., Hickman, M., Holmes, J., Kaner, E., \& Michie, S. (2016). Comparison of brief interventions in primary care on smoking and excessive alcohol consumption: A population survey in England. The British journal of general practice: the journal of the Royal College of General Practitioners, 66(642), e1-e9. https://doi.org/10.3399/bjgp16X683149

13) Broyles, L. M., Rosenberger, E., Hanusa, B. H., Kraemer, K. L., \& Gordon, A. J. (2012). Hospitalised patients' acceptability of nurse-delivered screening, brief intervention, and referral to treatment. Alcoholism, Clinical and Experimental Research, 36(4), 725-731. https://doi.org/10.1111/j.1530-0277.2011.01651.x

14) Calina, D., Hartung, T., Mardare, I., Mitroi, M., Poulas, K., Tsatsakis, A., Rogoveanu, I., \& Docea, A. O. (2021). COVID-19 pandemic and alcohol consumption: Impacts and interconnections. Toxicology Reports, 8, 529-535.

https://doi.org/10.1016/j.toxrep.2021.03.005

15) Campbell, C. (2018, September 27). Decline in alcohol per capita consumption in Grenada. NOW Grenada. https://www.nowgrenada.com/2018/09/decline-in-alcohol-per-capitaconsumption-in-grenada/

16) Catalano R., \& Bellows B. (2005). Commentary: If economic expansion threatens public health, should epidemiologists recommend recession? International Journal of Epidemiology. 34(6):1212-1213.

17) Catalano R., Novaco R., McConnell W. (1997) A model of the net effect of job loss on violence. Journal of Personality and Social Psychology. 72:1440-47.

18) Charveriat, C. (2000, October). Natural Disasters in Latin America and the Caribbean: An Overview of Risk. Inter-American Development Bank. https://www.preventionweb.net/files/2544_ENVNatDisastLACeline.pdf

19) Chodkiewicz, J., Talarowska, M., Miniszewska, J., Nawrocka, N., \& Bilinski, P. (2020). Alcohol consumption reported during the COVID-19 pandemic: The initial stage. International Journal of Environmental Research and Public Health, 17(13), 4677. https://doi.org/10.3390/ijerph17134677

20) de Goeij, M. C. M., Suhrcke, M., Toffolutti, V., van de Mheen, D., Schoenmakers, T. M., \& Kunst, A. E. (2015). How economic crises affect alcohol consumption and alcoholrelated health problems: A realist systematic review. Social Science \& Medicine, 131, 131-146. https://doi.org/10.1016/j.socscimed.2015.02.025

21) Doran, C.M., Digiusto, E., 2011. Using taxes to curb drinking: A report card on the Australian Government's alcopops tax. Drug Alcohol Review. 30 (6).

22) Douglas, D. (2019). Teenage Drinking in Grenada. Paradise: Maryzoon Press.

23) Douglas, C. (2006). A Sociological Analysis of Alcohol and Marijuana Use and Abuse among Young People in Grenada. Ministry of Social Development. Retrieved on October 9, 2021, from https://gov.gd/sites/default/files/egov/ncodc/A_Sociological_Analysis_of_Alcohol_and_Marijuanause_among....pdf

24) Drink Aware. (2021). The law on alcohol and under 18s. https://www.drinkaware.co.uk/facts/alcohol-and-the-law/thelaw-on-alcohol-andunder-18s

25) Dziadkiewicz, J., Pisani, A., \& Wong, R. (2015). Does a Recession have an impact on alcohol consumption? Deakin Papers on International Business Economics, 8(1). 
The Economic and Psychosocial Effects of COVID-19 on Alcohol Use in Grenada during Lockdown: A Discussion on Policy Solutions to Prevent Harmful Alcohol Consumption

26) Field, C. A., Klimas, J., Barry, J., Bury, G., Keenan, E., Smyth, B. P., \& Cullen, W. (2013). Problem alcohol use among problem drug users in primary care: A qualitative study of what patients think about screening and treatment. BMC Family Practice, 14, 98. https://doi.org/10.1186/1471-2296-14-98.

27) Garcia-Cerde, R., Valente, J. Y., Sohi, I., Falade, R., Sanchez, Z. M., \& Monteiro, M. G. (2021). Alcohol use during the COVID19 pandemic in Latin America and the Caribbean. Pan American Journal of Public Health, 45(52), 1-11. https://doi.org/10.26633/RPSP.2021.52

28) Garcia, L. P., \& Sanchez, Z. M. (2020). Alcohol consumption during the COVID-19 pandemic: A necessary reflection for confronting the situation. Consumo de álcool durante a pandemia da COVID-19: Uma reflexão necessária parao enfrentamento da situação. Cadernos de Saude Publica, 36(10), e00124520. https://doi.org/10.1590/0102$311 \times 00124520$

29) Gordon Stair, A., \& Pottinger, A. (2005). Disaster preparedness and management in the Caribbean: The need for psychological support. West Indian Medical Journal, 54(3). https://doi.org/10.1590/s0043-31442005000300001

30) Government of Grenada. (2021). Excise Tax. Inland Revenue Division. https://ird.gd/index.php/en/media-centre/pressreleases/205-property-tax-demandnotices-are-out

31) Government of Grenada. (2018, September). National Schools' Policy on Drugs. https://gov.gd/sites/moe/files/National\%20Schools\%20Policy\%20on\%20Drugs\%2C\% 202018\%20to\%202023.pdf

32) Governors Highway Safety Association. (2021). Alcohol Impaired Driving. GHSA. https://www.ghsa.org/statelaws/issues/alcohol\%20impaired\%20driving

33) Grenada Broadcasting Network. (2019, December 16). Stiff Fines for Failing Breathalyzer Tests. GBN. https://gbn.gd/police-to-introduce-breathalyzer-testing/

34) Grossman, E. R., Benjamin-Neelon, S. E., \& Sonnenschein, S. (2020). Alcohol consumption during the COVID-19 Pandemic: A cross-sectional survey of U.S. adults. International Journal of Environmental Research and Public Health, 17(24),

9189. https://doi.org/10.3390/ijerph17249189

35) Henry, A. (2021, May 12). Lawmakers raise drinking age to 18. Barbados Today. https://barbadostoday.bb/2021/05/12/lawmakers-raise-drinking-age-to-18/Hutchings, D., Cassidy, P., Dallolio, E., Pearson, P., Heather, N., \& Kaner, E. (2006).

36) Implementing screening and brief alcohol interventions in primary care: Views from both sides of the consultation. Primary Health Care Research \& Development, 7(3), 221-229. doi:10.1191/1463423606pc292oa

37) International Monetary Fund. (2020). The World Economic Outlook. International Monetary Fund. Washington, DC: Publication Services, International Monetary Fund. Retrieved from https://www.imf.org//media/Files/Publications/WEO/2020/April/English/text.ashx Japal, E., \& Benoit, O. (2017). A sociological perspective of alcohol use in the Caribbean. International Public Health Journal, 9, 7.

38) Johansson, K., Bendtsen, P., \& Akerlind, I. (2005). Factors influencing G.P.s' decisions regarding screening for high alcohol consumption: A focus group study in Swedish primary care. Public Health, 119(9), 781-788.

https://doi.org/10.1016/j.puhe.2004.12.006

39) Kasirye, R., \& Swahn, M. (2015, September 8). Integrating Alcohol Prevention Strategies and Policies by NGOs:Findings from Survey of 55 NGOs in East Africa. National Institute on Drug Abuse.

https://www.drugabuse.gov/international/abstracts/integratingalcohol-prevention-strategies-policies-by-ngosfindingssurvey-55-ngos-in-east-africa Kaner, E. F., Beyer, F. R., Muirhead, C., Campbell, F., Pienaar, E. D., Bertholet, N., Daeppen, J.

40) B., Saunders, J. B., \& Burnand, B. (2018). Effectiveness of brief alcohol interventions in primary care populations. The Cochrane Database of Systematic Reviews, 2(2), CD004148. https://doi.org/10.1002/14651858.CD004148.pub4

41) Killgore, W., Cloonan, S. A., Taylor, E. C., Lucas, D. A., \& Dailey, N. S. (2021). Alcohol dependence during COVID-19 lockdowns. Psychiatry Research, 296. https://doi.org/10.1016/j.psychres.2020.113676

42) Karlsson, T., Mäkelä, P., Österberg, E., \& Tigerstedt, C. (2010). A New Alcohol Environment: Trends in alcohol consumption, harms and policy: Finland 1990-2010. Nordic Studies on Alcohol and Drugs, 27(5), 497-514. https://doiorg.periodicals.sgu.edu/10.1177/145507251002700506

43) Liquor Dealers' Licences Act. (1988). (GREN). Retrieved from https://gov.gd/sites/default/files/docs/CAP\%20174Liquor\%20Dealers'\%20Licences\%20Act.pdf

44) Liquor Licence Act. (1974). (BER). Retrieved from

http://www.bermudalaws.bm/laws/Consolidated\%20Laws/Liquor\%20Licence\%20Ac t\%201974.pdf 
The Economic and Psychosocial Effects of COVID-19 on Alcohol Use in Grenada during Lockdown: A Discussion on Policy Solutions to Prevent Harmful Alcohol Consumption

45) Mcmanus, S., Hipkins, J., Haddad, P., Guthrie, E., \& Creed, F. (2003). Implementing an effective intervention for problem drinkers on medical wards. General Hospital Psychiatry, 25(5), 332-337. https://doi.org/10.1016/s0163-8343(03)000732

46) McPhee, M. D., Keough, M. T., Rundle, S., Heath, L. M., Wardell, J. D., \& Hendershot, C. S. Killgore, W., Cloonan, S. A., Taylor, E. C., Lucas, D. A., \& Dailey, N. S. (2021).

47) Alcohol dependence during COVID-19 lockdowns. Psychiatry Research, 296. https://doi.org/10.1016/j.psychres.2020.113676

48) McPhee, M. D., Keough, M. T., Rundle, S., Heath, L. M., Wardell, J. D., \& Hendershot, C. S. (2020). Depression, environmental reward, coping motives, and alcohol consumption during the COVID-19 pandemic. Frontiers in Psychiatry, 11, 114. https://doi.org/10.3389/fpsyt.2020.574676

49) Munne, M.I., 2005. Alcohol and the economic crisis in Argentina: recent findings. Addiction, 100(12).

50) Locke, S., Nguyen, A. M., Friedman, L., \& Gargano, L. M. (2020). Change in binge drinking behaviour after Hurricane Sandy among persons exposed to the 9/11 World Trade Center disaster. Preventive Medicine Reports, 19, 101144. https://doi.org/10.1016/j.pmedr.2020.101144

51) Miller, P. M., Thomas, S. E., \& Mallin, R. (2006). Patient attitudes towards self-report and biomarker alcohol screening by primary care physicians. Alcohol and Alcoholism (Oxford, Oxfordshire), 41(3), 306-310. https://doi.org/10.1093/alcalc/agl022

52) National Bureau of Economic Research. (2020, June 8). Determination of the February 2020 Peak in U.S. Economic Activity. https://www.nber.org/news/business-cycle-datingcommittee-announcement-june-8-2020

53) News Room. (2020, December 8). CARLTON HOUSE FOR 2021 / Grenada Broadcasting Network. GBN. https://gbn.gd/carlton-house-for-2021/

54) Nilsen, P., McCambridge, J., Karlsson, N., \& Bendtsen, P. (2011). Brief interventions in routine health care: A populationbased study of conversations about alcohol in Sweden. Addiction (Abingdon, England), 106(10), 1748-1756. https://doi.org/10.1111/j.13600443.2011.03476.x

55) Nordløkken, A., Pape, H., \& Heir, T. (2016). Alcohol consumption in the aftermath of a natural disaster: A longitudinal study. Public Health, 132, 33-39. https://doi.org/10.1016/j.puhe.2015.11.007

56) O'Donnell, A., Anderson, P., Newbury-Birch, D., Schulte, B., Schmidt, C., Reimer, J., \& Kaner, E. (2014). The impact of brief alcohol interventions in primary healthcare: A systematic review of reviews. Alcohol and Alcoholism (Oxford, Oxfordshire), 49(1), 66-78. https://doi.org/10.1093/alcalc/agt170

57) O'Donnell, A., \& Kaner, E. (2017). Are brief alcohol interventions adequately embedded in U.K. primary care? A qualitative study utilising normalisation process theory. International Journal of Environmental Research and Public Health, 14(4), 350. https://doi.org/10.3390/ijerph14040350

58) Organisation for Economic Co-operation and Development. (2015, July). Small island developing states (SIDS) and the post-2015 development finance agenda.

https://www.oecd.org/dac/financing-sustainabledevelopment/Addis\%20Flyer\%20SIDS\%20FINAL.pdf

59) Organisation for Economic Co-operation and Development. (2021, May), Preventing Harmful Alcohol Use, OECD Health Policy Studies, OECD Publishing, Paris, https://doi.org/10.1787/6e4b4ffb-en

60) Organisation for Economic Co-Operation and Development. (2021, May). The effect of Covid 19 on alcohol consumption and policy responses to prevent harmful alcohol consumption. OECD Policy Responses to Coronavirus (COVID-19). Retrieved on October 9, 2021, from https://www.oecd.org/coronavirus/policy-responses/the-effect-of-covid-19onalcohol-consumption-and-policy-responses-to-prevent-harmful-alcohol-consumption53890024/

61) Pan American Health Organization. (2020, September 9). Alcohol use during the COVID-19 pandemic in Latin America and the Caribbean, September 8, 2020 (Document No. PAHO/NMH/MH/Covid-19/20-0042).

https://iris.paho.org/handle/10665.2/52646

62) Perlman, F.J.A., 2010. Drinking in transition: Trends in alcohol consumption in Russia 1994- 2004. BMC Public Health, 10(691)

63) Popovici, I., \& French, M. T. (2013). Does unemployment lead to greater alcohol consumption? Industrial Relations: $A$ Journal of Economy and Society, 52(2), 444466.

64) Ramalho, R. (2020). Alcohol consumption and alcohol-related problems during the COVID-19 pandemic: A narrative review. Australasian Psychiatry: Bulletin of Royal Australian and New Zealand College of Psychiatrists, 28(5), 524-526. https://doi.org/10.1177/1039856220943024 
The Economic and Psychosocial Effects of COVID-19 on Alcohol Use in Grenada during Lockdown: A Discussion on Policy Solutions to Prevent Harmful Alcohol Consumption

65) Ruhm, C. (1995). Economic conditions and alcohol problems. Journal of Health Economics, 14(5), 583-603.

66) Ruhm C., Black W. (2002). Does drinking decrease in bad times? Journal of Health Economics, 21(4), 659-678.

67) Skog, O. J. (1986). An analysis of divergent trends in alcohol consumption and economic development. Journal of Studies on Alcohol, 47(1), 19-25. https://doi.org/10.15288/jsa.1986.47.19

68) Stanton, R., To, Q. G., Khalesi, S., Williams, S. L., Alley, S. J., Thwaite, T. L., ... Vandelanotte, C. (2020). Depression, anxiety and stress during COVID-19: Associations with changes in physical activity, sleep, tobacco and alcohol use in Australian adults. International Journal of Environmental Research and Public Health, 17(11), 4065. https://doi.org/10.3390/ijerph17114065

69) Straker, L. (2019, June 18). New drug and alcohol policy to be enforced in new school year. NOW Grenada. https://www.nowgrenada.com/2019/06/new-drug-and-alcohol-policy-to-beenforced-in-new-school-year/

70) The World Bank. (2020, June 8). COVID-19 to Plunge Global Economy into Worst Recession since World War II. https://www.worldbank.org/en/news/press-release/2020/06/08/covid-19-to-plunge-global-economy-into-worstrecession-sinceworld-war-ii

71) The World Bank. (2020). Grenada COVID-19 Crisis Response and Fiscal Management DPC. https://documents1.worldbank.org/curated/en/910171608519629297/pdf/Grenada-COVID-19-Crisis-Response-andFiscal-Management-Development-Policy-Credit.pdf

72) Tsai, J., Elbogen, E. B., Huang, M., North, C. S., \& Pietrzak, R. H. (2021). Psychological distress and alcohol use disorder during the COVID-19 era among middle- and low-income U.S. adults. Journal of Affective Disorders, 288, 41-49. https://doi.org/10.1016/j.jad.2021.03.085

73) United Nations Children's Fund. (1997, November). Juvenile Justice Information Portfolio - Committee on the Rights of the Child - 3. State Party Reports: Grenada. UNICEF. https://www.unicef-irc.org/portfolios/documents/386_grenada.htm

74) Valente, J. Y., Sohi, I., Garcia-Cerde, R., Monteiro, M. G., \& Sanchez, Z. M. (2021). What is associated with the increased frequency of heavy episodic drinking during the COVID19 pandemic? Data from the PAHO regional web-based survey. Drug and Alcohol Dependence, 221, 108621. https://doi.org/10.1016/j.drugalcdep.2021.108621

75) Walker, A. (2020, June 10). Coronavirus: U.K. economy could be among worst of leading nations, says OECD. BBC News, online Wagenaar, A. C., \& Streff, F. M. (1989). Macroeconomic conditions and alcohol-impaired driving. Journal of Studies on Alcohol, 50(3), 217-225. https://doi.org/10.15288/jsa.1989.50.217

76) World Health Organization. (2020, September). The impact of the COVID-19 pandemic of non-communicable disease resources and services: results of a rapid assessment. World Health Organization. https://www.who.int/publications/i/item/9789240010291

77) World Health Organization. (2018). Global status report on alcohol and health 2018. World Health Organization. https://apps.who.int/iris/handle/10665/274603. License: CC BYNC-SA 3.0 IGO

78) Wichaidit, W., Sittisombut, M., Assanangkornchai, S., \& Vichitkunakorn, P. (2021). Self-reported drinking behaviours and observed violation of state-mandated social restriction and alcohol control measures during the COVID-19 pandemic: Findings from nationallyrepresentative surveys in Thailand. Drug and Alcohol Dependence, 221. https://doi.org/10.1016/j.drugalcdep.2021.108607

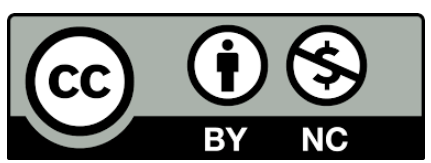

There is an Open Access article, distributed under the terma of the Creative Commons Attribution - Non Commercial 4.0 International (CC BY-NC 4.0)

(https://creativecommons.org/licenses/by-nc/4.0/), which permits remixing, adapting and building upon the work for non-commercial use, provided the original work is properly cited. 